\title{
ANÁLISE DO USO DA PONTUAÇÃO EM PRODUÇÕES DO ENSINO MÉDIO
}

\author{
Tatiane Cristina Becher* \\ Sanimar Busse
}

RESUMO: Considerando as reflexões sobre o funcionamento de mecanismos linguísticos que estabelecem o sentido no processo interlocutivo, preza-se pela pesquisa voltada ao ensino de habilidades específicas da Língua Portuguesa, como a escrita. No presente artigo, apresenta-se a análise do uso da pontuação em produções textuais escritas por alunos do Ensino Médio, na intenção de responder à pergunta: como os alunos tendem a pontuar seus textos a partir de encaminhamentos de produção textual? Os resultados compreendem um recorte da pesquisa realizada para a dissertação de mestrado, que partiu de uma diagnose inicial entre alunos do Ensino Médio. O aporte teórico baseia-se em autores como Halliday e Hasan (1976), Corrêa (1994), Dahlet (1995, 2006), Chacon (1996), Cunha e Cintra (2001), Bronckart (2003), Rajagopalan (2003), Marcuschi (2008), Koch (2010), Cunha e Saleh (2013), dentre outros. Os dados indicam que os alunos, em geral, tendem a não pontuar seus textos, o que se conjectura justificar-se pela não compreensão dos variados aspectos que envolvem o papel da pontuação, tanto em seu aspecto sintático-semântico quanto rítmico-prosódico e coesivo. Ressalta-se que pesquisas sobre os conhecimentos dos alunos da função e do uso dos mecanismos linguísticos, em especial os sinais de pontuação, levando em consideração as dificuldades que os participantes deste estudo demonstraram, colocam-se como imprescindíveis para que se possa buscar estratégias mais eficientes para o processo de ensino-aprendizagem da Língua Portuguesa.

PALAVRAS-CHAVE: Pontuação; Escrita; Produções textuais; Ensino; Língua portuguesa.

\footnotetext{
${ }^{*}$ Mestre em Letras pela Universidade Estadual do Oeste do Paraná (Unioeste).

${ }^{* *}$ Doutora em Estudos da Linguagem pela Universidade Estadual de Londrina (Uel). Professora efetiva da Universidade Estadual do Oeste do Paraná (Unioeste).
} 


\section{Introdução}

A leitura e a escrita estão presentes ao longo de todo o processo de formação do aluno, desde as séries iniciais até o Ensino Médio. Mesmo assim, constantes são as dificuldades demonstradas por estudantes de diferentes níveis escolares, desde os mais básicos até o ensino superior, no momento de expressar-se pela escrita. Em geral, essas dificuldades estão relacionadas, principalmente, à escolha vocabular, à argumentação, ao uso de conectores textuais, à ausência ou inconsistência no uso de sinais de pontuação, dentre outros.

Os problemas de escrita relacionados ao uso dos sinais de pontuação apresentamse de maneira recorrente em produções textuais, o que reflete a incompreensão sobre a função desses sinais como mecanismos organizadores do texto, que relacionam e delimitam ideias, estabelecem hierarquias e ordenações no corpo textual, de forma a garantir uma escrita coesa e coerente. A ausência ou o seu uso aleatório podem, na realidade, prejudicar a escrita, dificultando a compreensão do texto em decorrência da falta dessa hierarquização e da organização de ideias que podem ser estabelecidas pela pontuação.

A demanda por pesquisas acadêmicas na área de ensino de Língua Portuguesa nos instiga ao desenvolvimento deste estudo voltado para o uso de pontuação no Ensino Médio, refletindo sobre como atua sobre a escrita, tendo em vista as persistentes dificuldades demonstradas pelos alunos com relação ao seu uso e a inconsistência nas recomendações estabelecidas para a pontuação por diferentes gramáticas, as quais se demonstram insuficientes para contemplar os variados aspectos dos sinais da pontuação, tanto sintático-semânticos quanto rítmico-prosódicos.

Alguns dos problemas de escrita são mencionados, a partir de diferentes perspectivas, em pesquisas como as de: Pécora (1983), que identifica, no corpus de sua pesquisa, problemas relacionados principalmente à acentuação, pontuação, ortografia, norma padrão, emprego lexical, emprego de anafóricos, redundância, emprego de noções confusas, lugar-comum, dentre outros; Busse (2007), ao relatar a ausência de argumentação e posicionamento do aluno como interlocutor de seu texto; Freitas (2009), que descreve a dificuldade dos alunos para manter a coesão em seus textos e posicionar-se criticamente por meio da escrita; Santos (2014), o qual menciona a dificuldade dos alunos para compreender e 
produzir um texto escrito; Perroni (2015), que remete o uso aleatório dos sinais de pontuação à incompreensão de como esses sinais podem colaborar na escrita.

As pesquisas mencionadas distanciam-se por mais de uma década (de 1983 a 2015) e, mesmo assim, refletem a persistência de certas fragilidades no processo de ensino-aprendizagem da Língua Portuguesa, o que reafirma a necessidade de estudos que busquem alternativas para os problemas recorrentes na área.

Em situações formais de escrita, incluindo processos seletivos como o Exame Nacional do Ensino Médio (ENEM), o domínio da Língua Portuguesa é avaliado a partir dessas múltiplas habilidades, como a leitura e compreensão de diferentes modalidades de textos, a apropriação e o adequado uso da norma padrão na escrita da Língua Portuguesa, a clareza na escrita, a seleção de ideias e argumentos e a maneira como o aluno se posiciona como escritor ao defender suas afirmações. Etapas de avaliação como o ENEM refletem a importância desse conhecimento linguístico para alunos do Ensino Médio que pretendem ingressar em instituições de ensino superior e, portanto, reafirmam a necessidade de práticas de ensino que os auxiliem em seu processo de aprendizagem.

Esta pesquisa parte da análise de textos produzidos em uma etapa de diagnose inicial realizada em duas turmas do Ensino Médio, de colégios estaduais da cidade de Cascavel/PR, na qual se confirmaram significativas dificuldades apresentadas pelos alunos no que se refere ao uso da pontuação, em especial quanto às funções do ponto final e da vírgula. O projeto de pesquisa tramitou no Comitê de Ética em Pesquisa com Seres Humanos e foi aprovado sob o Parecer No 2.254.438, em 2017.

Diante das experiências com o ensino de Língua Portuguesa, o presente artigo possui como objetivo analisar o uso da pontuação em produções escritas do EM, buscando responder à seguinte pergunta: como os alunos tendem a pontuar seus textos a partir de encaminhamentos de produção textual?

Além das pesquisas previamente mencionadas, o aporte teórico deste estudo baseiase em autores como: Halliday e Hasan (1976), ao se tratar da noção de texto e coesão textual; Corrêa (1994) e Chacon (1996), com relação ao papel da pontuação textual; Cunha 
e Cintra (2001), ao se apresentarem principalmente as funções sintáticas da pontuação; Bronckart (2003), com relação à concepção de gênero; reflexões de Rajagopalan (2003) acerca da função social da Linguística e da linguagem; Koch (2010), nas compreensões sobre o texto, gênero, coesão e coerência textuais; Dahlet $(1995,2006)$, na apresentação das variadas funções da pontuação; Marcuschi (2008) e seu entendimento sobre texto, gênero, língua e linguagem; Cunha e Saleh (2013), sobre a pontuação no texto; dentre outros autores.

$\mathrm{O}$ artigo encontra-se organizado da seguinte maneira: nas duas primeiras seções, apresentam-se reflexões teóricas acerca da Linguística Textual, do ensino e das funções da pontuação no texto. $\mathrm{Na}$ sequência, apresentam-se a descrição da coleta dos dados e o levantamento e análise do corpus, seguidos das considerações finais do artigo.

\section{A linguística textual e o ensino}

Para Rajagopalan (2003), “A linguística é uma prática social como qualquer outra e tem por seu objeto a própria linguagem." (RAJAGOPALAN, 2003, p. 126). É por essa razão que muitas pesquisas são aportadas nos pressupostos teóricos da grande área da linguística e de suas vertentes, na intenção de refletir e mostrar a maneira como a linguagem permeia toda e qualquer prática social e a sua função crítica perante a sociedade, levando os sujeitos a se (re)inventarem de maneira constante a partir dessa linguagem.

Segundo Marcuschi (2008), a Linguística de Texto, doravante LT, surgiu nos anos 60 do século XX, preocupando-se apenas com textos escritos e seus processos de produção. Hoje, abrange estudos tanto da compreensão de textos escritos quanto de orais, sendo que seus interesses e objetivos se ampliaram nos anos 90. Pode-se definir a Linguística do Texto como "o estudo das operações linguísticas, discursivas e cognitivas reguladoras e controladoras da produção, construção e processamento de textos escritos ou orais em contextos naturais de uso." (MARCUSCHI, 2008, p. 73), assim como "uma perspectiva de trabalho com a língua que recusa a noção de autonomia da língua.” (MARCUSCHI, 2008, p. 75-76). 
Marcuschi (2008) destaca que a motivação inicial da LT foi a compreensão de que certas propriedades linguísticas de uma frase só poderiam ser explicadas considerando sua relação com outras frases, o que exigia uma teoria que superasse os limites da linguística da frase - daí as denominadas "relações interfrásticas". Além de situar-se nos domínios da linguística, a LT lida com os fatos da língua e considera a sociedade em que essa língua se situa, trabalhando com fatos mais amplos do que a linguística tradicional. Contudo, aspectos estritamente linguísticos - como a fonologia, a morfologia, a sintaxe e a semântica - são imprescindíveis para a estabilidade textual e estão pressupostas quando se analisa o texto.

Os apontamentos de Marcuschi (2008), ao tratar da linguagem como fenômeno inserido em contextos comunicativos diversos, vão ao encontro das reflexões de Rajagopalan (2003), o qual se refere à linguagem como uma prática social, assim como a linguística também o é; a linguística considerada crítica parte do princípio de que trabalhar com a linguagem é necessariamente intervir na realidade social da qual ela faz parte.

No que concerne a compreensão de "texto", Guimarães (2004) descreve o texto como qualquer enunciado, verbal ou escrito, extenso ou curto, antigo ou moderno, assim como Halliday e Hasan (1976) consideram um texto como falado ou escrito, em prosa ou em verso, em forma de monólogo ou diálogo, abrangendo desde um simples provérbio até uma peça completa, desde um grito para se pedir ajuda até uma discussão em um comitê que dure um dia; os autores ressaltam, ainda, que o texto representa uma unidade semântica, não se tratando de uma unidade de forma, mas sim de uma unidade de significado.

Neste artigo, concebe-se a compreensão de texto como estrutura, consoante a Guimarães (2004) e Halliday e Hasan (1976), em decorrência do fato de o objeto de estudo com o qual aqui se trabalha, a pontuação, figurar-se em um elemento da língua restrito ao texto escrito, ou seja, que ocorre na materialidade do texto.

\section{As funções da pontuação no texto}

A partir do levantamento de alguns estudos realizados acerca do uso das marcas de pontuação na modalidade escrita, percebe-se que a noção de pontuação surgiu, de fato, 
como uma marcação das pausas na leitura em voz alta. Moreno (2011) afirma que "[...] da Antiguidade Clássica até o fim da Idade Média, praticamente só se lia em voz alta; a leitura silenciosa era quase desconhecida e, como se vê em comédias gregas e romanas, considerada um hábito de malucos e excêntricos” (MORENO, 2011, p. 10).

Segundo Cunha e Saleh (2013), “a pontuação está constantemente presente em nossas leituras e produções, mesmo que de modo não consciente, desde nossas primeiras letras" (CUNHA; SALEH, 2013, p. 263).

Dahlet (1995) aponta a adaptação do sistema de pontuação à evolução histórica, sendo que apenas no século XVIII atribuiu-se o funcionamento semântico à pontuação. No século XIX, a leitura vocalizada foi substituída pela silenciosa, em razão da formação de cada vez mais leitores e, principalmente, da evolução sociológica do impresso, que possibilitou o distanciamento cada vez maior entre o momento da redação e da leitura. Porém, a pontuação ainda é muitas vezes considerada subordinada à leitura em voz alta e, por consequência, à respiração.

Segundo Busse e Gedoz (2014),

O uso adequado dos sinais de pontuação é um dos elementos indispensáveis para a elaboração de textos coesos e coerentes e que atendam a uma função social definida. Pontuar é dispor e demarcar os sentidos que o texto quer transmitir na interação que se estabelece com o leitor. A pontuação contribui para a organização das informações do texto e permite ao produtor estabelecer o encadeamento das ideias na construção de sentidos numa dada situação discursiva. Na produção escrita, pontuar nem sempre é uma tarefa de fácil execução. (BUSSE; GEDOZ, 2014, p. 243)

Morris e Hirst (1991) refletem sobre a importância de estruturas linguísticas que organizam o texto, cada uma delas com uma função distinta, sendo que os limites dos enunciados podem, às vezes, parecer confusos, mas alguns fatores auxiliam seu esclarecimento, como palavras-chaves, mudanças na entonação (em textos orais) e mudanças de aspectos textuais e de tempos verbais. 
Dentre os distintos mecanismos voltados à garantia desses limites dos enunciados, uma das estruturas da língua que conferem maior organização ao texto é o uso dos sinais de pontuação.

Diferentemente das letras, que remetem a um tipo de percepção espacial da cadeia sonora, os sinais de pontuação marcam na escrita o limite da possibilidade de segmentação. Ocupam uma zona de instabilidade entre a possibilidade de divisão dos espaços de sentido (no nível sintático, entonacional ou rítmico) e a impossibilidade de lhes atribuir limites preciosos. (CORRÊEA, 1994, p. 53)

Para Moreno (2011), somos mais facilmente compreendidos quando falamos do que quando escrevemos, pois, na fala, há a entonação, o ritmo, as pausas, os gestos e as expressões faciais, que servem como uma espécie de manual de instruções, auxiliando-nos a fazer com que o outro a quem falamos compreenda nossa real intenção. Na escrita, um dos artefatos que nos auxilia na compreensão de nossos textos são os sinais de pontuação, os quais funcionam como sinalizadores para o leitor, assim como placas de trânsito para um motorista.

Koch (2010) considera os sinais de pontuação (vírgula, ponto e vírgula, dois pontos, ponto) como elementos sequenciadores de justaposição que estabelecem um sequenciamento coesivo entre porções maiores ou menores da superfície textual, da mesma forma que Passos (1959) afirma que, sem a pontuação, teria o leitor de reler e tresler, às vezes, para de fato compreender o sentido da frase, prejudicando, assim, o contexto geral do escrito.

Cagliari (1989) apresenta o tom atribuído ao texto por diferentes recursos sinalizadores de padrões entoacionais, como o caso da vírgula, que indica um tom suspensivo; do ponto final, que indica um tom de asserção; do ponto de interrogação, que indica um tom de pergunta; do ponto de exclamação, que pode indicar um enunciado exclamativo, pressupondo o desconhecimento prévio da informação por parte do ouvinte, ou reforçando um conhecimento prévio compartilhado entre os interlocutores, ou, ainda, representando 
apenas uma afirmativa mais enfática; dentre outros. Segundo o autor, "esses valores entoacionais são dados pelo contexto do discurso e pelo uso do sinal de pontuação." (CAGLIARI, 1989, p. 196-197)

Segundo Cunha e Cintra (2001), o ponto e a vírgula, assim como o ponto-e-vírgula, são considerados sinais de pontuação pertencentes a um mesmo grupo: aquele que compreende os sinais destinados à marcação das pausas. A inexistência ou precariedade dessas marcas de pontuação pode, em muitos casos, comprometer a intenção do escritor de se expressar de maneira clara e consistente, por meio de uma tessitura coesiva e coerente, própria do sujeito competente quanto ao uso da linguagem nas mais diversas situações, para os mais diversos fins de comunicação, que escreve com o propósito não apenas de comunicar, mas se fazer ouvir, marcar sua opinião e atitude perante a sociedade.

Pode-se perceber, a partir da perspectiva de diferentes pesquisadores, uma das principais funções atribuídas à pontuação em um texto: a contribuição com a garantia da coesão e da coerência. A falta de domínio das articulações possíveis de serem estabelecidas pelos sinais de pontuação pode acarretar complicações na compreensão de um texto, enquanto que o entendimento sobre como usar tais marcadores textuais contribui em muito para a clareza das ideias do autor desse texto.

Além da contribuição que a pontuação oferece à coesão e à coerência textual, há seu funcionamento sintático na Língua Portuguesa escrita. As funções sintáticas atribuídas aos sinais de pontuação funcionam como reguladores de seu papel na construção de um texto coeso, ainda que, de acordo com Cunha e Saleh (2013), a falta de consenso entre autores quanto ao funcionamento desses sinais dificulte a uniformização de suas funções sintáticas.

Considera-se importante atentar-se não somente às funções coesivas da pontuação, mas também à compreensão de seu funcionamento na sintaxe do Português, em especial para a análise deste trabalho, na qual se abordam funções distintas do ponto e da vírgula, verificando o número de ocorrências com base em explicações sintáticas e refletindo sobre os diferentes papeis da pontuação. 
Segundo Cunha e Cintra (2001), a pontuação opera na língua escrita como uma colaboradora para suprir a carência dos inúmeros recursos rítmicos e melódicos dos quais dispõe a língua falada. Para os autores, os sinais fundamentalmente destinados a marcar sobretudo as pausas no texto escrito são a vírgula, e ponto e o ponto-e-vírgula. Os sinais de pontuação geralmente indicam, ao mesmo tempo, a pausa e a melodia. Para Chacon (1996), "as vírgulas, delimitando, na escrita, estruturas que, na oralidade, seriam expressas com entoação suspensiva, criam no leitor a sensação de continuidade do enunciado e não a de seu término" (CHACON, 1996, p. 134).

Com relação ao ponto final, a maioria dos gramáticos afirma ser a função do ponto encerrar períodos que terminem por qualquer tipo de oração que não seja interrogativa direta ou exclamativa; Cunha e Cintra (2001) afirmam que "emprega-se, pois, fundamentalmente, [o ponto] para indicar o término de uma oração declarativa, seja ela absoluta, seja a derradeira de um período composto." (CUNHA; CINTRA, 2001, p. 651)

Para Dahlet (2006), a homogeneização da pontuação justifica-se pela contribuição acadêmica do século XX, que passaram a utilizar os sinais de pontuação baseando-se nas gramáticas. No entanto, os manuais de gramática apresentam um conteúdo sistematizado sobre o assunto, não dando conta de abarcar a complexidade dos sinais de pontuação no discurso cotidiano. Segundo a autora, a pontuação apresenta uma plurifuncionalidade: sintática, semântica, expressiva e supra-segmental.

Apesar da não uniformidade das regulamentações quanto ao uso dos sinais de pontuação entre os gramáticos, considera-se importante compreender o funcionamento desses elementos na superfície textual enquanto mecanismos reguladores e modalizadores de períodos dentro de um texto e, além disso, considerar os parâmetros estabelecidos pela norma padrão da língua, uniformemente aceitos em diversas situações, como em vestibulares, concursos e exames a nível nacional.

\section{Coleta de dados}


O intuito norteador desta pesquisa foi estudar a realidade da escrita na escola, em especial da escrita dos alunos no Ensino Médio. Percebeu-se a questão do uso da pontuação como relevante para a investigação acadêmica ao serem verificados diversos casos de incompreensão dos alunos quanto ao uso desses sinais no texto escrito. Essa percepção foi obtida a partir da aplicação de uma proposta inicial de escrita em dois colégios públicos da região, que envolveu um relato pessoal e um comentário crítico. Essa proposta investigativa inicial não será aqui descrita de maneira detalhada, uma vez que este artigo propõe apresentar os dados decorrentes da análise da aplicação da unidade didática (UD) posteriormente aplicada em um desses colégios em que se deu a investigação inicial da pesquisa.

O corpus a ser aqui analisado consiste em 86 textos escritos durante a aplicação da UD desenvolvida para o trabalho com a pontuação em sala de aula. Os 86 textos que compõem a amostra foram escritos por 25 alunos que participaram da etapa de aplicação da proposta. A UD apresenta quatro propostas principais de escrita, além de diversos exercícios que envolvem a pontuação em diferentes gêneros textuais: a primeira proposta de produção textual consiste em uma simulação de um post em um canal do YouTube ${ }^{\circledR}$ sobre leitura e escrita; a segunda refere-se à simulação de um post online em um blog sobre o bullying; a terceira e a quarta propostas consistem em textos dissertativo-argumentativos sobre o bullying e o preconceito linguístico, respectivamente.

Opta-se, novamente, por não detalhar mais profundamente a UD ou os exercícios que acompanharam as propostas, uma vez que o foco deste trabalho está voltado à análise dos resultados obtidos a partir da análise dos textos dos alunos.

\section{Como os alunos pontuam seus textos}

Entende-se que as práticas de ensino da língua não devem se restringir ao seu funcionamento exclusivamente prescritivo-normativo ao considerarmos que, consoante $\mathrm{Cu}$ nha e Saleh (2013) e Cegalla (2000), o uso sancionado dos sinais de pontuação não é unanimemente aceito por todos os autores, pois consistem em mecanismos complexos com 
múltiplas funções no corpo do texto escrito, o que não permite restringir seus funcionamentos como unicamente sintáticos, coesivos ou melódicos. Ressalta-se, mais uma vez, que esses diferentes aspectos da pontuação se complementam e se relacionam, sendo que, por esse motivo, não podem ser tomados como absolutos ou completos.

No entanto, as classificações de problemas baseadas na gramática normativa definidas neste trabalho justificam-se na intenção de facilitar a quantificação, análise e compreensão dos tipos de problemas que ocorrem na escrita dos alunos quanto ao uso desses sinais, buscando entender se tais desvios caracterizam uma maior ausência de pontuação ou uso aleatório, por exemplo, de forma a considerar tanto as funções sintáticas quanto as funções coesivas e melódicas da pontuação na análise do corpus.

A partir dos dados obtidos, estabeleceu-se uma classificação mais abrangente das ocorrências que representam algum tipo de problema, separando-as em casos de "ausência de pontuação", "uso desnecessário de pontuação" e "troca de sinais de pontuação". Tais ocorrências encontram-se expostas e quantificadas em porcentagem por meio da Figura 01, abaixo:

Figura 01 - Classificação dos problemas de pontuação da Amostra 2

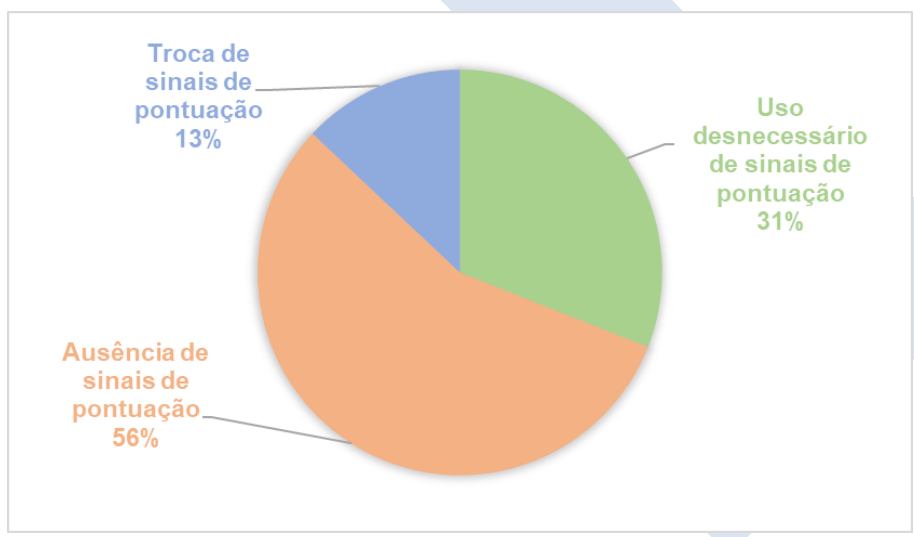

Fonte: desenvolvido pela pesquisadora, 2018 
Como se pode perceber, a maioria dos casos está relacionada à ausência de pontuação, o que se conjectura justificar-se pela não compreensão dos alunos quanto ao funcionamento dos sinais, levando-os a não pontuarem seus textos. Para maior compreensão da maneira como os alunos utilizam-se ou não da pontuação, são apresentadas, na sequência, as quantificações de cada classificação, assim como exemplos de alguns dos casos mais recorrentes na amostra. Os excertos apresentados foram transcritos exatamente como escritos pelos alunos, optando por não sinalizar ou corrigir outros desvios da norma padrão identificados. As classificações sintáticas estabelecidas para a análise dos dados são baseadas em gramáticos como Cunha e Cintra (2001), Cegalla (2000), Bechara (2009), Sacconi (2011), Faraco e Moura (1996).

No quadro 01, a seguir, apresenta-se o levantamento dos casos classificados como ausência de pontuação, em ordem decrescente de ocorrência.

Quadro 01 - Ausência de pontuação

\begin{tabular}{|l|c|c|c|c|c|}
\hline Ausência de sinais de pontuação & $\begin{array}{c}\text { TEXTO 1 } \\
\text { (POST } \\
\text { YOUTUBE) }\end{array}$ & $\begin{array}{c}\text { TEXTO 2 } \\
\text { (POST } \\
\text { BLOG) }\end{array}$ & $\begin{array}{c}\text { TEXTO 3 } \\
\text { (BUL- } \\
\text { LYING) }\end{array}$ & $\begin{array}{c}\text { TEXTO 4 } \\
\text { (Preconceito } \\
\text { Linguístico) }\end{array}$ & Soma \\
\hline $\begin{array}{l}\text { a) ausência de vírgula para separar } \\
\text { adjuntos adverbiais deslocados }\end{array}$ & 9 & 8 & 13 & 8 & 38 \\
\hline $\begin{array}{l}\text { b) ausência de vírgula para separar } \\
\text { orações subordinadas adverbiais } \\
\text { (desenvolvidas ou reduzidas) }\end{array}$ & 9 & 9 & 6 & 9 & 33 \\
\hline $\begin{array}{l}\text { c) ausência de vírgula para separar } \\
\text { orações coordenadas sindéticas e } \\
\text { assindéticas (com exceção das inici- } \\
\text { adas pela conjunção aditiva "e") }\end{array}$ & 13 & 3 & 1 & 1 & 18 \\
\hline $\begin{array}{l}\text { d) ausência de vírgula para isolar } \\
\text { conjunções adversativas ou conclu- } \\
\text { sivas intercaladas }\end{array}$ & 2 & 5 & 5 & 5 & 13 \\
\hline $\begin{array}{l}\text { e) ausência de vírgula para separar } \\
\text { expressões de caráter explicativo ou } \\
\text { corretivo, como "isto é", "ou me- } \\
\text { lhor", "por exemplo", etc. }\end{array}$ & 3 & 4 & 3 & 1 & 11 \\
\hline $\begin{array}{l}\text { f) ausência de vírgula para separar } \\
\text { uma oração coordenada sindética } \\
\text { adversativa iniciada com a conjun- } \\
\text { ção "mas" }\end{array}$ & 9 & 0 & 0 & 1 & 10 \\
\hline
\end{tabular}




\begin{tabular}{|l|c|c|c|c|c|}
\hline $\begin{array}{l}\text { g) ausência de vírgula antes de } \\
\text { "etc" ou reticências }\end{array}$ & 5 & 0 & 1 & 1 & 7 \\
\hline $\begin{array}{l}\text { h) ausência de vírgula para isolar } \\
\text { um aposto }\end{array}$ & 1 & 1 & 0 & 3 & 5 \\
\hline $\begin{array}{l}\text { i) ausência de vírgula para separar } \\
\text { orações subordinadas adjetivas ex- } \\
\text { plicativas }\end{array}$ & 2 & 3 & 0 & 0 & 5 \\
\hline $\begin{array}{l}\text { j) ausência de vírgula para realçar os } \\
\text { adjuntos adverbiais "sim" e não" } \\
\text { como resposta afirmativa e negativa }\end{array}$ & 3 & 0 & 0 & 0 & 3 \\
\hline $\begin{array}{l}\text { k) ausência de ponto final para indi- } \\
\text { car o término de uma oração decla- } \\
\text { rativa }\end{array}$ & 1 & 1 & 1 & 0 & 3 \\
\hline $\begin{array}{l}\text { l) ausência de vírgula para separar } \\
\text { elementos com mesma função sin- } \\
\text { tática em uma enumeração }\end{array}$ & 2 & 0 & 0 & 0 & 2 \\
\hline $\begin{array}{l}\text { m) ausência de vírgula para isolar } \\
\text { sujeito deslocado na frase }\end{array}$ & 0 & 0 & 0 & 2 & 2 \\
\hline $\begin{array}{l}\text { n) ausência de vírgula para separar } \\
\text { orações intercaladas e/ou de cará- } \\
\text { ter explicativo }\end{array}$ & 0 & 0 & 0 & 1 & 1 \\
\hline
\end{tabular}

Fonte: desenvolvido pela pesquisadora, 2018

Os casos de ausência da pontuação percebidos como os mais recorrentes na análise do corpus estão relacionados ao uso da vírgula para isolar adjuntos adverbiais deslocados e orações subordinadas adverbiais (desenvolvidas ou reduzidas), os quais geralmente devem ser isolados por vírgulas, consoante a Cunha e Cintra (2001). O excerto 1, abaixo, exemplifica os casos classificados como “a) ausência de vírgula para separar adjuntos adverbiais deslocados":

EXCERTO 1 (texto dissertativo-argumentativo sobre preconceito linguístico)

(1) "Muitas das vezes o preconceito se forma a partir do pensamento etnocêntrico $[\ldots]^{\prime \prime}$

No excerto 1, o adjunto adverbial de frequência “muitas das vezes" poderia ser isolado por vírgulas no início da oração. De acordo com Chacon (1996), ao se isolar estruturas que dão ênfase a alguma informação específica (como a frequência de uma ocorrência, 
no caso do excerto 1), destaca-se uma alternância prosódico-semântica entre as diferentes partes do enunciado.

EXCERTO 2 (post blog sobre bullying)

(2) "Diante dos fatos preocupantes já expostos seria conveniente por parte das escolas prestar auxílio psicológico à esses indivíduos [...]”

O caso apresentado no excerto 2 caracteriza o que pode ser considerado destaque de informações, sintaticamente classificado como separação de oração subordinada adverbial (“diante dos fatos preocupantes já expostos"). O termo "por parte das escolas" pode ser classificado como agente da passiva e encontra-se intercalado na frase. Portanto, isolálo por vírgulas confere maior organização ao período, uma vez que o termo representa uma quebra na ideia de que "seria conveniente prestar auxílio psicológico a esses indivíduos", facilitando, assim a leitura. Passos (1959) afirma que a pontuação estabelece ao leitor a ordem lógica do pensamento, tornando o texto mais claro e evitando que a leitura precise ser feita mais do que uma vez. Caso fossem estabelecidas pausas ao intercalar os termos "diante dos fatos preocupantes já expostos" e "por parte das escolas" por vírgulas, o uso desses sinais facilitaria a leitura por funcionarem como elementos que organizam as ideias estabelecidas, isolando elementos deslocados e enfatizando elementos explicativos, por exemplo.

No quadro 02, apresentado na sequência, expõe-se o levantamento dos casos classificados como usos desnecessários de pontuação, em ordem decrescente de ocorrência.

Quadro 02 - Usos desnecessários de pontuação

\begin{tabular}{|l|c|c|c|c|l|}
\hline $\begin{array}{l}\text { Uso desnecessário de sinais de } \\
\text { pontuação }\end{array}$ & $\begin{array}{c}\text { TEXTO 1 } \\
\text { (POST }\end{array}$ & $\begin{array}{c}\text { TEXTO 2 } \\
\text { (POST }\end{array}$ & $\begin{array}{c}\text { TEXTO 3 } \\
\text { (BUL- }\end{array}$ & $\begin{array}{c}\text { TEXTO 4 } \\
\text { (Preconceito }\end{array}$ & Soma \\
& YOUTUBE) & BLOG) & LYING) & Linguístico) & \\
\hline
\end{tabular}




\begin{tabular}{|c|c|c|c|c|c|}
\hline $\begin{array}{l}\text { a) uso da vírgula para separar o su- } \\
\text { jeito do predicado (termos essenci- } \\
\text { ais da oração) }\end{array}$ & 0 & 0 & 20 & 10 & 30 \\
\hline $\begin{array}{l}\text { b) separação de outros termos es- } \\
\text { senciais e integrantes da oração, } \\
\text { que não devem ser separados por } \\
\text { vírgula }\end{array}$ & 1 & 7 & 9 & 10 & 27 \\
\hline $\begin{array}{l}\text { c) vírgula antes da conjunção adi- } \\
\text { tiva "e" }\end{array}$ & 4 & 2 & 1 & 3 & 10 \\
\hline $\begin{array}{l}\text { d) uso da vírgula para separar VTD } \\
\text { e OD (termos essenciais e integran- } \\
\text { tes da oração) }\end{array}$ & 1 & 0 & 2 & 2 & 5 \\
\hline $\begin{array}{l}\text { e) uso desnecessário de vírgula an- } \\
\text { tes e depois da conjunção explica- } \\
\text { tiva "pois" }\end{array}$ & 1 & 1 & 1 & 2 & 5 \\
\hline $\begin{array}{l}\text { f) separação de pronome relativo e } \\
\text { complemento por vírgula }\end{array}$ & 0 & 0 & 0 & 2 & 2 \\
\hline $\begin{array}{l}\text { g) uso da vírgula para separar a ora- } \\
\text { ção principal de uma oração subor- } \\
\text { dinada substantiva }\end{array}$ & 0 & 0 & 1 & 1 & 2 \\
\hline h) reticências após "etc" & 1 & 0 & 0 & 0 & 1 \\
\hline $\begin{array}{l}\text { i) separação de oração adjetiva res- } \\
\text { tritiva com vírgula }\end{array}$ & 0 & 1 & 0 & 0 & 1 \\
\hline
\end{tabular}

Fonte: desenvolvido pela pesquisadora, 2018

Os casos considerados usos desnecessários de pontuação são aqueles em que há uma marcação de pausa entre termos que, em geral, não requerem qualquer separação por vírgula ou por ponto final, como demonstrado nos exemplos abaixo:

EXCERTO 3 (post blog sobre bullying)

(3) "As escolas, devem entrar com um recurso, para se pronunciar sobre tal assunto $[\ldots]^{\prime \prime}$

No trecho acima, exemplifica-se um dos casos mais recorrentes na análise de uso desnecessário da vírgula: “a) uso da vírgula para separar o sujeito do predicado (termos essenciais da oração)". A recomendação sintática estabelece a não separação de tais elementos, por complementarem-se de maneira mais próxima sintaticamente. Pensando no 
aspecto rítmico-semântico do uso da vírgula, tampouco há a necessidade de tal separação, pois mesmo como elemento articulador da entonação na língua escrita tal representação não seria necessária nesse caso.

O uso excessivo da vírgula parece ser uma tentativa de atribuir maior formalidade ao texto, o que pode estar relacionado ao gênero no qual o aluno escreve, pois os casos de separação de sujeito e predicado ocorreram exclusivamente nas propostas 3 e 4 de escrita, que correspondem a textos dissertativo-argumentativos. Nas duas primeiras propostas de escrita, simulando posts em ambientes online, não há qualquer ocorrência como essa. Tal descoberta pode ser justificada pelo estilo da escrita em cada gênero, considerando que, segundo Bronckart (2003), a pré-existência de gêneros empíricos e históricos gera ao leitor certo conhecimento intuitivo das regras e propriedades específicas de cada gênero, semelhante a um senso comum que já espera certa regularidade nas reorganizações de cada gênero.

Assim sendo, admite-se levantar a hipótese de que, em gêneros com maior monitoramento quanto ao funcionamento da escrita em conformidade com a norma padrão da Língua Portuguesa, em especial contextos em que a ordem sintática é ressaltada, como vestibulares e exames avaliativos, há uma maior preocupação do aluno em utilizar sinais de pontuação como a vírgula, levando-o a hipercorreções como essas verificadas na análise. O uso excessivo de pontuação reflete, mais uma vez, a incompreensão dos alunos quanto ao funcionamento da escrita e, além disso, pode representar uma tentativa de atribuir maior formalidade ao texto, consoante a seu gênero.

A seguir, apresenta-se o levantamento dos casos classificados como trocas de sinais de pontuação.

Quadro 03 - Troca de sinais de pontuação

\begin{tabular}{|l|c|c|c|c|l|}
\hline \multirow{3}{*}{ Troca de sinais de pontuação } & TEXTO 1 & TEXTO 2 & TEXTO 3 & TEXTO 4 & \\
& (POST & (POST & (BUL- & (Preconceito \\
& YOUTUBE) & BLOG) & LYING) & Linguístico) & \\
\hline
\end{tabular}




\begin{tabular}{|l|l|l|l|l|l|}
\hline $\begin{array}{l}\text { a) uso da vírgula ao invés do ponto } \\
\text { final para indicar o término de uma } \\
\text { oração declarativa }\end{array}$ & 12 & 8 & 3 & 2 & $\mathbf{2 5}$ \\
\hline $\begin{array}{l}\text { b) uso inadequado da conjunção } \\
\text { "e" ao invés de vírgulas para sepa- } \\
\text { rar elementos com a mesma função } \\
\text { sintática em uma enumeração }\end{array}$ & 4 & 1 & 0 & 0 & $\mathbf{5}$ \\
\hline $\begin{array}{l}\text { c) uso da vírgula após a conjunção } \\
\text { (adversativa/conclusiva) ao invés } \\
\text { de antes }\end{array}$ & 3 & 0 & 0 & 0 & $\mathbf{3}$ \\
\hline $\begin{array}{l}\text { d) uso do ponto ao invés da vírgula } \\
\text { para separar oração coordenada } \\
\text { sindética explicativa }\end{array}$ & 0 & 1 & 0 & 0 & $\mathbf{1}$ \\
\hline $\begin{array}{l}\text { e) uso de ponto ao invés de vírgula } \\
\text { para separar palavras e expressões } \\
\text { explicativas, retificativas ou conti- } \\
\text { nuativas como "isto é", "por exem- } \\
\text { plo", "ou melhor", etc. }\end{array}$ & 1 & 0 & 0 & 0 & $\mathbf{1}$ \\
\hline
\end{tabular}

Fonte: desenvolvido pela pesquisadora, 2018

Os casos de uso da vírgula apenas após a conjunção (adversativa/conclusiva), ao invés de utilizar a vírgula antes da conjunção, também foram considerados como uma troca, no sentido em que houve a percepção de que uma marca de pausa seria, de fato, necessária, porém o sinal não foi utilizado com precisão, alterando a posição em que tal pausa deveria ocorrer. Alguns exemplos dos casos de trocas de sinais de pontuação encontram-se expostos abaixo:

EXCERTO 4 (post YouTube sobre leitura e escrita)

(4) "Não gosto muito de escrever, a minha escrita não é muito boa, cometo alguns erros de concordancia, entre outras coisas, acho que consigo expressar minhas opiniões, sempre que escrevo tento passar minha opinião sobre tal assunto, já vivenciei um mal entendido devido à minha escrita a pessoa interpretou de forma que pensou que eu estava sendo ironico." 
Ao relatar sua percepção sobre si enquanto escritor(a), o(a) autor(a) desse texto elenca várias informações novas sobre sua habilidade de escrita: A) "Não gosto muito de escrever"; B) "a minha escrita não é boa"; C) "cometo alguns erros de concordância, entre outras coisas"; D) "Acho que consigo expressar minhas opiniões"; E) "sempre que escrevo tento passar minha opinião sobre tal assunto"; F) “já vivenciei um mal entendido devido à minha escrita"; G) "a pessoa interpretou de forma que pensou que eu estava sendo irônico". Essas sete afirmativas complementam-se ao mesmo tempo em que se diferem entre si, cada uma delas representando um núcleo de informação nova sobre o assunto discorrido.

Percebe-se, nesse parágrafo, um elenco de informações que se dá pelo uso exclusivo de vírgulas. No entanto, tal escolha deixa de lado a multiplicidade de funções atribuídas aos sinais de pontuação no texto escrito. Para Cagliari (1989), a vírgula indica um tom suspensivo, enquanto o ponto final indica um tom de asserção, quer dizer, a vírgula estabelece uma pausa mais próxima a uma continuação, enquanto o ponto final delimita afirmações, ao mesmo tempo em que organiza o parágrafo e a relação entre essas diferentes asserções. O caso apresentado neste excerto representa a classificação “a) uso da vírgula ao invés do ponto final para indicar o término de uma oração declarativa”.

Dessa maneira, poderia ser atribuída maior coesão ao excerto 4 se reescrito como: "Não gosto muito de escrever. A minha escrita não é muito boa, cometo alguns erros de concordância, entre outras coisas. Acho que consigo expressar minhas opiniões, sempre que escrevo tento passar minha opinião sobre tal assunto. Já vivenciei um mal-entendido devido à minha escrita, pois a pessoa interpretou de forma que pensou que eu estava sendo irônico." Nesse caso de troca dos sinais de pontuação, é possível notar, a partir da análise e possível reescrita do parágrafo, a maneira como a pontuação constitui o sentido e a organização da escrita, o que reflete na coesão do texto, uma vez que, segundo Koch (2010), o conceito de coesão textual diz respeito aos processos que asseguram uma ligação linguística significativa entre os elementos da superfície textual. A pontuação corresponde a um dos mecanismos mais próximos do nível microtextual que auxiliam nessa ligação significativa 
entre diferentes elementos do texto. Outros elementos conectivos como conjunções e pronomes relativos também poderiam ser utilizados para auxiliar essa organização das ideias apresentadas no excerto.

EXCERTO 5 (post blog sobre bullying)

(5) “A utilização de novas informações em escolas, televisão, redes sociais, etc. pode ser uma forma de auxílio para crianças e adolescentes. Porque muitos têm medo de contar para familiares e amigos que sofrem bullying."

No caso apresentado pelo excerto 5, há uma ideia principal ("A utilização de novas informações em escolas, televisão, redes sociais, etc. pode ser uma forma de auxílio para crianças e adolescentes") e uma justificativa para tal asserção ("Porque muitos têm medo de contar para familiares e amigos que sofrem bullying"). A segunda afirmação não apenas complementa, mas justifica a primeira, sendo, portanto, sintaticamente classificada como uma oração coordenada explicativa. Recomenda-se, nesse caso, o uso da vírgula para indicar essa relação mais próxima entre as orações, aproximando as ideias ao invés de demarcar uma pausa maior entre elas. Esse foi o único caso percebido na amostra de "c) uso do ponto ao invés da vírgula para separar oração coordenada sindética explicativa”. Considera-se válido destaca-lo para demonstrar, mais uma vez, a importância da pontuação textual, uma vez que a quebra de expectativa estabelecida pelo uso do ponto ao invés da vírgula nesse exemplo confunde o leitor do texto, que espera uma relação explicativa entre as afirmações, o que não demanda uma marcação de pausa por ponto, distanciando orações, na verdade, possuem uma relação de ideias mais próximas entre si.

Morris e Hirst (1991) enfatizam a importância das funções desempenhadas por diferentes estruturas linguísticas, sendo que os limites dos enunciados podem, às vezes, parecer confusos, mas alguns fatores auxiliam seu esclarecimento. Considera-se o funcionamento de cada sinal de pontuação um desses fatores cooperantes ao esclarecimento dos limites de cada enunciado, como foi possível perceber na análise desses excertos. 
No entanto, na enumeração utilizada nesse parágrafo, verifica-se o domínio do aluno quanto ao uso de vírgulas em “escolas, televisão, redes sociais, etc.”. Apenas dois casos de ausência de vírgula para separar elementos com mesma função sintática em uma enumeração foram constatados na amostra, o que representa a compreensão dos alunos quanto a essa função coesiva da vírgula.

Como se pode perceber por meio da análise realizada, é veemente a importância do trabalho com a pontuação em sala de aula, inclusive no EM, consoante à persistência dos problemas aqui observados. Os alunos continuam apresentando dificuldades recorrentes quanto à utilização desses sinais, o que se conjectura justificar-se pela inexistência de uma unanimidade quanto à explicação do funcionamento da pontuação, uma vez que esta possui múltiplos papeis no texto.

\section{Considerações finais}

As reflexões e análises quanto ao processo de ensino-aprendizagem da escrita e suas particularidades nos levam ao reconhecimento de lacunas e possibilidades quanto ao ensino da Língua Portuguesa, sondando o comportamento linguístico dos alunos quanto a habilidades específicas no conhecimento da Língua Portuguesa, como o uso da pontuação para uma escrita coesa e coerente, considerando que cabe à escola promover práticas que levem o aluno a compreender as múltiplas funções de mecanismos linguísticos como os sinais da pontuação e os usos da linguagem em interações sociais de múltiplas naturezas.

As constantes dificuldades apresentadas pelos alunos com relação à leitura e à escrita justificam a demanda por pesquisas acadêmicas e pela elaboração de propostas de ensino voltadas à área. O objetivo deste artigo consistiu em analisar o uso da pontuação em produções escritas do EM, buscando responder à seguinte pergunta: como os alunos tendem a pontuar seus textos a partir de encaminhamentos de produção textual?

Considera-se a pergunta de pesquisa respondida a partir dos levantamentos de dados apresentados quanto às ocorrências de problemas relacionados à pontuação verificados e a partir da análise de excertos retirados da amostra. Descobriu-se que a maior parte dos 
alunos tende a não utilizar os sinais de pontuação, o que se percebe acontecer devido à sua incompreensão quanto às múltiplas funções desses mecanismos linguísticos no texto. Percebeu-se, também, a influência do gênero textual no comportamento linguístico do aluno, uma vez que a maior formalidade do gênero os levou à hipercorreção no uso da vírgula.

Em geral, os alunos demonstram dificuldade para reconhecer a informação principal e, consequentemente, os limites de cada enunciado, de cada ideia nova. Como a pontuação não corresponde à transcrição de pausas da fala (uma vez que fala e escrita são conceitos completamente distintos), ela não faz parte da gramática internalizada do aluno. É preciso compreender como cada sinal funciona na materialidade do texto, sistematizar esse conhecimento por meio da prática da leitura e da escrita e conscientizar o estudante dos limites das regras gramaticais e das diversas funções dos sinais de pontuação.

É por essa razão que as práticas de ensino que envolvem pontuação devem conscientizar o aluno das diferentes funções da pontuação, sem restringir-se apenas às funções sintáticas, englobando também as funções coesivas, além do aspecto rítmico-prosódico e rítmico-semântico como fatores cooperativos na construção textual, incentivando a prática da leitura e da escrita no âmbito escolar, no intuito de auxiliar o aluno a incorporar os diferentes funcionamentos dos sinais de pontuação e a maneira como auxiliam na construção de sentido no texto.

\section{ANALYSIS OF THE USE OF PUNCTUATION IN HIGH SCHOOL COMPOSITIONS}

ABSTRACT: Considering the reflections on the functioning of linguistic mechanisms that establish the meaning in the interlocutive process, there is great value to the research focused on teaching specific skills of the Portuguese Language, such as writing. In the present article, the analysis of the use of punctuation in written compositions of high school students is presented, with the intention of answering the question: how do students tend to punctuate their texts when receiving written composition proposals? The results are part of a research conducted for the master's thesis, which started from an initial investigation with high school students. The theoretical basis relies on authors such as Halliday and Hasan (1976), Corrêa (1994), Dahlet (1995, 2006), Chacon (1996), Cunha and Cintra (2001), Bronckart (2003), Rajagopalan (2003), Marcuschi (2008), Koch (2010), Cunha and Saleh (2013), among others. The data indicate that students, in general, tend not to punctuate their texts, which is conjectured to be justified by the lack of understanding of the various aspects that involve the role of punctuation, both in its syntactic-semantic, rhythmic-prosodic and cohesive aspect. It is noteworthy that research on students' knowledge of the function and use of linguistic 
mechanisms, specially the punctuation marks, taking into account the difficulties that the participants of this study demonstrated, are essential for the search for more effective strategies for the teachinglearning process of the Portuguese language.

KEYWORDS: Punctuation; Writing; Written Compositions; Teaching; Portuguese language

\section{REFERÊNCIAS}

BECHARA, Evanildo. Moderna gramática portuguesa. 37 ed. Rio de Janeiro: Nova Fronteira, 2009.

BRONCKART, Jean-Paul. Gêneros textuais, tipos de discursos e operações psicolinguísticas. Revista de Estudos da Linguagem, Belo Horizonte, v. 11, n. 1, p. 49-69, 2003. Disponível em: < http://www.periodicos.letras.ufmg.br/index.php/

relin/article/view/2344/2293> Acesso em: 16 fev. 2018.

BUSSE, Sanimar; GEDOZ, Sueli. A pontuação e seus efeitos de sentido: elementos para a leitura. In: COSTA-HÜBES, Terezinha da Conceição et. al. (Org.). Descritores da Prova Brasil ( $5^{\circ}$ Ano): estudos e proposições didáticas. São Carlos: Pedro \& João Editores, 2014, p. 243-262.

CAGLIARI, L.C. Marcadores prosódicos na escrita. In: Seminário do grupo de estudos lingüísticos, 18, 1989, Lorena. Anais do XVIII Seminário do Gel. Lorena: Grupo de Estudos Lingüísticos de São Paulo, 1989. p. 195-203. Disponível em:

<http://www.gel.org.br/arquivo/anais/1309090746_26.cagliari_luiz.pdf> Acesso em: 22 fev. 2018.

CEGALLA, Domingos Paschoal. Novissima gramática da lingua portuguesa. São Paulo: Editora Nacional, 2000.

CHACON, Lourenço. Ritmo da escrita: uma organização do heterogêneo da linguagem. 1996. 389 f. Tese (Doutorado em Estudos da Linguagem). Universidade Estadual de Campinas, Instituto de Estudos da Linguagem, São Paulo, 1996.

CORRÊA, Manoel Luiz Gonçalvez. Pontuação: sobre seu ensino e concepção. Revista Leitura: teoria e prática, Revista semestral da Associação de Leitura do Brasil, $\mathrm{N}^{\circ} 24$, p. 52-65, dez./1994.

CUNHA, Celso; CINTRA, Luís F. Lindley. Nova gramática do português contemporâneo. $3^{\mathrm{a}} \mathrm{ed}$. Rio de Janeiro: Nova Fronteira, 2001.

CUNHA, Franciane Aparecida da; SALEH, Pascoalina Bailon de Oliveira. A pontuação em material de cursinho preparatório para vestibular. In: VII Ciclo de Estudos da Linguagem, 2013, Ponta Grossa/PR. Anais do VII Ciclo de Estudos da Linguagem, 2013. Disponível em: <http://sites.uepg.br/ciel/2013/files/ANAIS.pdf>. Acesso em: 7 jul. 2018. 
DAHLET, Véronique Braun. Pontuação, língua, discurso. In: XXIV Seminario do GEL, 1995, São Paulo. Estudos Lingüisticos. Anais de Seminarios do GEL XXIV. São Paulo:

GEL Est. de São Paulo, 1994. v. 1. p. 337-340.

GUIMARÃES, Elisa. A articulação do texto. 9a ed. São Paulo: Ática, 2004. . As (man)obras da pontuação: usos e significações. São Paulo: Associação Editorial Humanitas, 2006.

FARACO, Carlos Emílio; MOURA, Francisco Marto de. Gramática. 16 ed. São Paulo: Ática, 1996.

HALLIDAY, Michael Alexander Kirkwood; HASAN, Ruqaiya. Cohesion in English. London: Longman, 1976.

KOCH, Ingedore G. Villaça. A coesão textual. 22a ed. São Paulo: Contexto, 2010.

MARCUSCHI, Luiz Antônio. Produção textual, análise de gêneros e compreensão. São Paulo: Parábola Editorial, 2008.

MORENO, Cláudio. Guia prático do português correto: para gostar de aprender, v. 4, pontuação. Porto Alegre: L\&PM, 2011.

MORRIS, Jane; HIRST, Graeme. Lexical cohesion computed by thesaural relations as an indicator of the structure of text. Computational Linguistics, 1(17):21-43, 1991. Disponível em: <http://dl.acm.org/citation.cfm?id=971740>. Acesso em: 9 ago. 2017.

PASSOS, Alexandre. Arte de pontuar: noções sintáticas. $5^{\text {a }}$ ed. Rio de Janeiro: Irmãos Pongetti Editores, 1959.

RAJAGOPALAN, Kanavillil. Por uma linguística crítica: linguagem, identidade e questão ética. São Paulo: Parábola Editorial, 2003.

SACCONI, Luiz Antonio. Novíssima gramática ilustrada. 24 ed. São Paulo: Nova Geração, 2011.

Recebido em: 19/10/2019. Aprovado em: $13 / 01 / 2020$. 